\title{
Persistent Primitive Trigeminal Artery Imaged by Three-dimensional Computed Tomography Angiography -Two Case Reports-
}

\author{
Yasuhiro SUZUKI, Norihiko KUNII, and Kiyoshi MATSUMOTo \\ Department of Neurosurgery, Showa University School of Medicine, Tokyo
}

\begin{abstract}
Three-dimensional computed tomography (3D CT) angiography was used to investigate two cases of persistent primitive arteries. 3D CT angiography and 3D CT demonstrated a persistent primitive trigeminal artery variant penetrating the lateral edge of the posterior clinoid process and running to the posterior medial side, and a persistent primitive trigeminal artery perforating the canal of the posterior clinoid process and the petrosal bone junction. 3D CT angiography can delineate these persistent primitive arteries and the anatomy relative to the bone structure simultaneously, so is very useful to identify the arterial line where the canal is penetrated.
\end{abstract}

Key words: persistent primitive trigeminal artery, persistent primitive trigeminal artery variant, three-dimensional computed tomography angiography

\section{Introduction}

Persistent primitive artery is a well-known anomaly identified by angiography or magnetic resonance (MR) angiography. However, the exact location of the perforation of the skull base by these arteries is impossible to identify by these methods. Patients with persistent primitive artery associated with vascular malformation, cerebral aneurysm, or trigeminal neuralgia may require surgical treatment. Therefore, the relationship between these arteries and the skull base structure must be assessed accurately. Three-dimensional computed tomography (3D CT) angiography can visualize both the skull base and the blood vessels simultaneously, so is very useful to understand the anatomical relationship of these structures. We describe cases of persistent primitive trigeminal artery (PTA) and PTA variant (PTAV) identified by 3D CT angiography and digital subtraction angiography.

\section{Case Reports}

Case 1: A 63-year-old male was admitted to our hospital with mild right hemiparesis on April 21, 1993. CT demonstrated right putaminal hemorrhage with a volume of about $10 \mathrm{ml}$. He was treated conservatively and discharged after one month. Four years later he felt slight dizziness with unspecified complaints. MR angiography performed at the same time showed an abnormal artery branching from the precavernous portion of the internal carotid artery. The bilateral vertebral arteries and basilar artery could not be seen clearly. He was admitted on October 15, 1997 with suspected ischemia around the posterior fossa.

Neurological examination on admission found mild right hemiparesis. 3D CT angiography showed the artery penetrating the right lateral edge of the posterior clinoid process and running to the posterior medial side at the clivus (Fig. 1 left). Right carotid angiography showed the abnormal artery branching from the precavernous portion of the internal carotid artery, running to the posterior medial side, then branching to right and left and flowing into the area of the superior cerebellar artery. The right posterior cerebral artery was filled through the posterior communicating artery (Fig. 1 center, right). Bilateral vertebral angiography showed the bilateral vertebral arteries and the basilar artery providing slight flow into the area of the posterior inferior cerebellar artery and superior cerebellar artery. 



Fig. 1 Case 1. left: Three-dimensional computed tomography angiogram showing the abnormal artery (arrows) penetrating the right lateral edge of the posterior clinoid process and running to the posterior medial side at the clivus. center, right: Right carotid angiograms, anteroposterior (center) and lateral (right) views, showing the abnormal artery, identified as a persistent primitive trigeminal artery variant, branching from the precavernous portion of the internal carotid artery, running to the posterior medial side, branching to right and left, and flowing into the area of the superior cerebellar artery (arrows). The right posterior cerebral artery is filled through the posterior communicating artery (arrowhead).

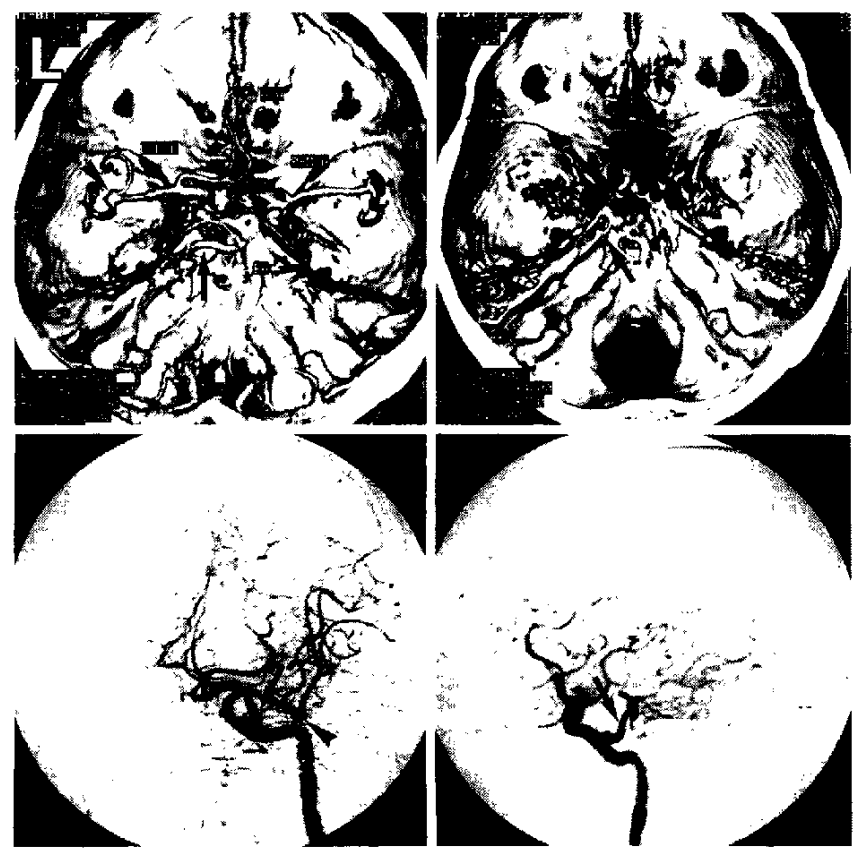

However, there was no communication between the PTAV and the vertebrobasilar arteries. The vascular anomaly was identified as PTAV based on these findings.

We doubted that his complaints were caused by the anomaly, so he was treated conservatively after discharge.

Case 2: A 77-year-old male was referred to our
Fig. 2 Case 2. upper left: Three-dimensional computed tomography (3D CT) angiogram showing the left middle cerebral artery (MCA) aneurysm (arrowhead) and the persistent primitive trigeminal artery (PTA) (arrow). upper right: 3D CT scan showing the canal (arrow) through which the PTA perforates the area between the posterior clinoid process and the petrosal bone junction. lower row: Left carotid angiograms, anteroposterior (left) and lateral (right) views, demonstrating the PTA (arrow) and the left MCA aneurysm (arrowhead). The PTA branches from the precavernous portion of the internal carotid artery posteriorly, runs to the posterior medial side, and flows into the area of the bilateral posterior cerebral and superior cerebellar arteries. hospital with dizziness on May 7,1998 . He had complained of the same symptom for about 4 years. He had a past history of hypertension and surgical treatment for cervical spondylosis.

Neurological examination on admission found hyperreflexia of the bilateral biceps, patellar and Achilles tendon reflexes, but no paresis, sensory disturbance, or cerebellar signs. MR imaging 
showed lacunar infarct in the basal ganglia. 3D CT angiography showed the left middle cerebral artery aneurysm and PTA (Fig. 2 upper left). 3D CT showed the canal formed by the PTA perforation between the posterior clinoid process and the petrosal bone junction (Fig. 2 upper right). Left carotid angiography demonstrated the PTA branched from the precavernous portion of the internal carotid artery posteriorly, ran to the posterior medial side, and flowed into the area of the bilateral posterior cerebral and superior cerebellar arteries (Fig. 2 lower row). Left vertebral angiography showed the vertebral artery was filled until the top of the basilar artery. This suggested that the vertebrobasilar arteries communicated with the PTA.

We proposed surgical treatment for the aneurysm, but the patient refused consent. Therefore, he has been observed as an outpatient until now.

\section{Discussion}

Helical CT allows the imaging of thin slices in a short time, with greatly improved quality based on recent developments in technology. 3D CT can be used to image skull base lesions that are difficult to visualize by bone window CT and to determine the treatment plan. ${ }^{2,24,30,32)} 3 \mathrm{D} \mathrm{CT}$ angiography is now widely used for the diagnosis of aneurysms and ischemic cerebrovascular disease. 3D CT angiography is excellent for observation of multi-projection and stereoscopic views, and the high-spatial resolution enables easy understanding of the anatomical relationships between bone and blood vessels. ${ }^{25}$

PTA is the most common of the persistent primitive arteries. ${ }^{1,7)}$ PTA originates from the internal carotid artery at the $\mathrm{C}_{4}$ (cavernous portion) or $\mathrm{C}_{4}$ and $\mathrm{C}_{5}$ (petrosal portion) junction. PTA shows two patterns: direct perforation of the central portion of the dorsum sellae and anastomosis with the basilar artery ${ }^{17]}$; and running along the lateral portion of the dorsum sellae, turning toward the central side, and anastomosis with the basilar artery. ${ }^{9}$ ) $3 \mathrm{D}$ CT angiography showed that the PTA in our case perforated the canal between the posterior clinoid process and the petrosal bone junction (Fig. 2 upper row). PTA can be classified into four types according to the anastomosis between the internal carotid artery and the basilar artery. ${ }^{13,18)}$ The most common pattern, as found in our case, is type 1 that flows into the bilateral posterior cerebral and superior cerebellar arteries.

PTAV is a similar abnormality which originates from the internal carotid artery and does not anastomose with the basilar artery but flows directly into the cerebellar area. Since the first case in
$1972,{ }^{26)}$ there have been 72 reported cases of PTAV. ${ }^{3-5,10-12,14,16,18)}$ Most cases flowed into the area of the anterior inferior cerebellar artery, and a few cases flowed into the area of the superior cerebellar artery or posterior inferior cerebellar artery. PTAV mainly originates from the precavernous portion and rarely from the cavernous portion, perforates Meckel's cave or the isolated dural foramen, runs behind the clivus along the trigeminal nerve in the posterior fossa, ${ }^{211}$ and flows into the area of the anterior inferior cerebellar artery. ${ }^{25 l}$ Exactly where the PTAV perforates the skull base is unclear, but 3D CT angiography showed that the PTAV perforated the lateral side of dorsum sellae and ran into the posterior fossa in our case.

Persistent primitive arteries are usually found incidentally, ${ }^{8,15,19,28)}$ but are often associated with vascular malformation ${ }^{20,29)}$ and cerebral aneurysm. ${ }^{1,6,7,15,18,31)}$ PTAV may be responsible for ischemia and trigeminal neuralgia. ${ }^{15,21,22,26,27]}$ Consequently, patients with these diseases associated with PTA or PTAV may require surgical treatment, especially trigeminal neuralgia, whether the abnormal artery is identified incidentally or symptomatically. Therefore, the structures of these persistent primitive arteries must be assessed accurately. No descriptions about exact location of persistent primitive arteries perforating the skull base are available, except for a case of persistent primitive hypoglossal artery. ${ }^{25)}$ 3D CT angiography allowed observation of the vessels and the skull base structure and assessment of their relationship based on multiple and stereoscopic views in the present two cases. However, 3D CT angiography cannot delineate vessels of less than $1 \mathrm{~mm}$ in diameter, ${ }^{23)}$ and the phenomenon of partial volume average mimics destruction by a lesion if normal thin bone is not contained completely in one slice. ${ }^{30}$ Therefore, 3D CT angiograms require careful evaluation as the basis of a diagnosis. Further use and development of 3D CT angiography will demonstrate the anatomical details of localization and variation in the skull base perforated area.

\section{References}

1) Agnoli AL: Vascular anomalies and subarachnoid haemorrhage associated with persisting embryonic vessels. Acta Neurochir (Wien) 60: 183-199, 1982

2) Ali QM, Dietrich B, Becker H: Patterns of skull base fracture: A three-dimensional computed tomographic study. Neuroradiology 36: 622-624, 1994

3) Chambers AA, Lukin R: Trigeminal artery connection to the posterior inferior cerebellar arteries. Neuroradiology 9: 121-123, 1975

4) Cobb SR, Hieshima GB, Mehiringer CG, Grinnell VS, 
Pribram HW: Persistent trigeminal arterial variation. Carotid anterior inferior cerebellar artery anastomosis. Surg Neurol 49: 263-266, 1983

5) Dilenge $D$, Heon $M$ : The internal carotid artery, in: Radiology of the Skull and Brain, vol 2. Saint Louis, CB Mosby, 1974, pp 1202-1245

6) Eadie MJ, Jamieson KG, Lennon EA: Persistent carotid-basilar anastomosis. J Neurol Sci 1: 501-511, 1964

7) George AE, Lin JP, Moranz RA: Intracranial aneurysm on a persistent trigeminal artery: Case report. J Neurosurg 35: 601-604, 1971

8) Harada K, Uozumi T, Kurisu K, Sumida M, Nakahara A, Migita K: [Evaluation of cerebro-vascular diseases with persistent carotid-basilar anastomosis]. No Shinkei Geka 22: 1153-1158, 1994 (Jpn, with Eng abstract)

9) Harrison CR, Luttrell C: Persistent carotid-basilar anastomosis: Three angiographically demonstrated cases with one anatomical specimen. J Neurosurg 10: 205-215, 1953

10) Harwood-Nash DC, Fitz CR: Neuroradiology in Infants and Children. Saint Louis, CB Mosby, 1976, pp 356-357

11) Haugton VM, Rosenbaum AE, Pearce J: Internal carotid artery origins of the inferior cerebellar arteries. AJR Am J Roentgenol 130: 1191-1192, 1978

12) Higano $S$, Uemura $K$, Ogawa $T$, Inugami $A$, Yamaguchi $T$, Shishido $F$, Suzuki S: [Persistent trigeminal artery variant. A case report of 5 cases and some embryological considerations]. Rinsho Hoshasen 32: 263-268, 1987 (Jpn, with Eng abstract)

13) Hinck VC, Gordg PD: Persistent primitive trigeminal artery: One type of persistent carotid-basilar anastomosis. Radiology 83: 41-45, 1964

14) Ito J, Takeda $N$, Suzuki $Y$, Takeuchi $S$, Osugi $S$, Yoshida $Y$ : Anomalous origin of the anterior inferior cerebellar arteries from the internal carotid artery. Neuroradiology 19: 105-109, 1980

15] Kadota $K$, Asakura $T$, Nakamura $K$, Kasamo $S$, Hirahara K: [Persistent carotid-basilar anastomosis. Analysis of 13 consecutive cases and review of literatures]. No Socchu 12: 293-300, 1990 (Jpn, with Eng abstract)

16) Katsuragi M, Inoue $Y$, Ueda J, Fukuzumi A, Matsuo N, Ohue S, Ozaki M, Iwasaki S, Odani R: [An anomalous branch of the internal carotid artery supplying vessels of posterior fossa directly]. No To Shinkei 32: 515-521, 1980 (Jpn, with Eng abstract)

17) Keppes J, Kernohan JW: Persistent-carotid basilar anastomosis: report of a case. J Neuropathol Exp Neurol 17: 631-634, 1958

18) Kimura $T$, Ueda $T$ : [Variant type of persistent-primitive trigeminal artery. Report of a case and assessment of reported case]. No Socchu 17: 379-386, 1995 (Jpn, with Eng abstract)

19) Kodama N, Watanabe $Z$, Sasaki $T$, Watanabe $M$, Yamao N, Tanji H, Nishizaka T: [Direct surgical obliteration of a persistent trigeminal artery aneurysm]. No Shinkei Geka 12: 325-329, 1984 (Jpn, with
Eng abstract)

20) Miyake $S$, Kikuchi $H$, Kondoh S: Treatment of a giant aneurysm of the cavernous internal carotid artery associated with a persistent primitive trigeminal artery: case report. Neurosurgery 26: 315-319, 1990

21) Morita A, Fukushima T, Miyazaki S, Shimizu T, Atsuchi M: Tic douloureux caused by primitive trigeminal artery of its variant. J Neurosurg 70: 415419, 1989

22) Nioka $H$, Nakazawa $T$, Matsuda $M$, Handa J: [Cerebral aneurysms associated with persistent primitive trigeminal artery. Report of three cases]. No Socchu 15: 216-224, 1993 (Jpn, with Eng abstract)

23) Suzuki $Y$, Kawamata T, Matsumoto H, Matsumoto K: [Detection of middle cerebral artery stenosis using 3D-CTA and MRA]. No Shinkei Geka Journal 7: 541547, 1998 (Jpn, with Eng abstract)

24) Suzuki $Y$, Kawamata T, Matsumoto $H$, Matsumoto K: [A case of brain abscess following frontal sinusitis: Usefulness of 3D-CT imaging of destructive lesions in the skull base]. No Shinkei Geka Journal 7: 639-643, 1998 (Jpn, with Eng abstract]

25) Takahana $Y$, Uno E, Wakamatsu K, Okada Y, Kaneko $\mathrm{T}$, Tsuchiya $\mathrm{Y}$ : [Three-dimensional computerized tomography angiography in a persistent primitive hypoglossal artery: A case report]. No Shinkei Geka Journal 7: 125-128, 1998 (Jpn, with Eng abstract)

26) Teal JS, Rumbaugh CL, Bergeron RT, Scanlan RS, Segall HD: Persistent carotid-superior cerebellar artery anastomosis: A variant of persistent trigeminal artery. Radiology 103: 335-341, 1972

27) Tokimura $H$, Atsuchi $M$, Kawasaki $T$, Sato $E$, Todoroki K, Asakura T, Fukushima T: [Trigeminal neuralgia associated with primitive trigeminal artery: Report of two cases]. No Shinkei Geka 18: 209213, 1990 (Jpn, with Eng abstract)

28) Tomsick TA, Lukin RR, Chambers AA: Persistent trigeminal artery: Unusual associated abnormalities. Neuroradiology 17: 253-257, 1979

29) Tsuboi $K$, Shibuya F, Yamada $T$, Nose T: Giant aneurysm at the junction of the left internal carotid and persistent primitive trigeminal arteries: Case report. Neurol Med Chir (Tokyo) 32: 778-781, 1992

30) Tsuchiya K, Tominaga M, Mizutani $Y$, Hachiya J: [Bone-display three-dimensional CT in the diagnosis of skull base tumors]. CI Kenkyu 17: 351-356, 1993 (Jpn, with Eng abstract)

31) Watanabe T, Aoki A, Chan SC: [Two cases of persistent trigeminal artery variant]. No Shinkei Geka 16: 95-100, 1988 (Jpn, with Eng abstract)

32] Yano K, Kuroda T, Tanabe $Y$, Takao A, Sakai N: Three-dimensional computed tomography imaging of a frontal skull base fracture: Case report. Neurol Med Chir (Tokyo) 37: 837-840, 1997

Address reprint requests to: $Y$. Suzuki, M.D., Department of Neurosurgery, SECOMEDIC Hospital, 696-1 Toyotomi-cho, Funabashi, Chiba 274-0053, Japan. 